\title{
PENGHAPUSAN ADAT RESAM MASYARAKAT DUSUN DI KIMANIS SEMASA PENTADBIRAN BRITISH NORTH BORNEO CHARTERED COMPANY 1881-1941
}

\section{ELIMINATION OF DUSUN COMMUNITY TRADITIONS IN KIMANIS DURING BRITISH NORTH BORNEO CHARTERED COMPANY ADMINISTRATION 1881-1941}

\author{
Afiratul Adawiyah Binti Dulkarim ${ }^{1}$ \& Siti Aidah Binti Hj Lukin @ Lokin ${ }^{2}$ \\ ${ }^{1}$ Fakulti Kemanusiaan Seni dan Warisan, Universiti Malaysia Sabah \\ ${ }^{2}$ Pusat Penataran Ilmu dan Bahasa, Universiti Malaysia Sabah \\ afiratuladawiyah94@gmail.com \\ sitiaida@ums.edu.my
}

\begin{abstract}
Custom in general means the habit in a society that is the rule of life and the punishment is appropriate according to their respective offenses. In Sabah, people used to practice the traditions and customs of their ancestors, led by Orang Tua and village head. The Sabah administration had many changed especially during the administration of the British North Borneo Chartered Company, BNBCC in 1881. These alterations eventually gave some effects on the Dusun community customs. Therefore, this paper aims to identify the abolition of customs during the BNBCC rule against the Dusun community in Kimanis. During the reign of the Sultanate of Brunei in Sabah before 1881, the customs practices of the Dusun community did not experience any restrictions or obstacles but they were free to live their lives in accordance with their respective customs. The method of data collection is through the reference of primary and secondary sources that can be found in the Archives and libraries. An interview session was also conducted on the head of the Dusun customs in Kimanis to identify the forms of customs that had been removed. Through this paper, it is found that the BNBCC administration has indeed eliminated some of the Dusun customs that have a profound effect on the Dusun community today.
\end{abstract}

Key words: Customs, BNBCC, Dusun, Sabah, Kimanis

\begin{abstract}
ABSTRAK
Adat secara umumnya bermaksud kebiasaan dalam sesebuah masyarakat yang menjadi peraturan hidup dan hukumannya pula sesuai mengikut kesalahan masing-masing. Di Sabah, dahulunya masyarakat mengamalkan amalan tradisi dan adat warisan nenek moyang yang diketuai oleh Orang Tua dan ketua kampung. Pentadbiran di Sabah mengalami banyak perubahan lebih-lebih lagi semasa pentadbiran British North Borneo Chartered Company (BNBCC) pada tahun 1881. Perubahan ini akhirnya mendatangkan kesan khususnya terhadap adat resam masyarakat Dusun. Oleh itu, artikel ini bertujuan untuk mengenalpasti penghapusan adat resam semasa pemerintahan BNBCC terhadap masyarakat Dusun di Kimanis. Semasa
\end{abstract}


pemerintahan Kesultanan Brunei di Sabah iaitu sebelum tahun 1881, amalan adat istiadat masyarakat Dusun tidak mengalami sebarang sekatan atau halangan malahan mereka bebas menjalani kehidupan sesuai dengan adat masing-masing. Kaedah kutipan data adalah melalui rujukan sumber primer dan sekunder yang boleh didapati di Arkib negeri Sabah dan perpustakaan negeri Sabah serta perpustakaan Universiti Malaysia Sabah. Sesi temu bual kepada Ketua Adat masyarakat Dusun di Kimanis juga dijalankan bagi mengenalpasti bentukbentuk adat yang telah dihapuskan semasa pentadbiran BNBCC. Melalui artikel ini, didapati bahawa pentadbiran BNBCC sememangnya menghapuskan sebahagian adat istiadat masyarakat Dusun Kimanis yang memberi kesan mendalam terhadap masyarakat Dusun ini pada masa kini.

Kata Kunci : Adat, BNBCC, Dusun, Sabah, Kimanis.

\section{Pengenalan}

Di Sabah, setiap etnik memiliki adat masing-masing yang sudah lama diamalkan sebelum kedatangan BNBCC lagi. Sejak zaman dahulu, masyarakat sudah diajar secara informal berkenaan adat resam tradisional masing-masing yang perlu diikuti dan dijadikan sebagai satu peraturan hidup berikutan tidak ada undang-undang bertulis yang formal. Keadaan ini menyebabkan masyarakat mencipta adat berdasarkan kefahaman mereka tentang alam semulajadi melalui pengalaman serta pengamatan masing-masing. Masyarakat Dusun mengamalkan tradisi yang diwarisi daripada nenek moyang mereka secara turun temurun Amalan ini dipupuk sejak kecil sehingga mereka mampu membentuk identiti budaya masyarakat Dusun. Namun demikian, apabila BNBCC mula mentadbir Sabah dengan membawa beberapa dasar baharu dalam bidang politik, ekonomi dan sosial mereka di samping wujudnya pengaruh agama Kristian akhirnya menyebabkan ada sebahagian adat masyarakat Dusun telah terhapus.

\section{Sorotan Literatur}

Pelbagai gambaran boleh dilihat berhubung dengan masyarakat Dusun di Kimanis antaranya mengenai kekuatan dan keberanian yang dimiliki oleh mereka sehingga mampu menundukkan beberapa masyarakat Dusun di daerah lain. Hal ini telah dijelaskan dalam penulisan Peter Phelan dalam Traditional Stone and Wood Monuments of Sabah iaitu berkenaan kegagahan Orang Kaya Pulang sekaligus memperlihatkan ketinggian rasa hormat dalam kalangan masyarakat Dusun di Penampang dan Putatan terhadap masyarakat Dusun di Kimanis. Peristiwa ini turut digambarkan dalam penulisan Sejarah dan Warisan Kimanis hasil penulisan Baszley Bee Hj. Basrah dan Zainuddin Baco. Selain itu, masyarakat ini juga terkenal dengan kekayaan adat resam yang diamalkan sejak turun temurun. Namun, masih belum banyak penulisan yang dihasilkan secara terperinci khususnya berkaitan dengan masyarakat ini.

Walau bagaimanapun, beberapa ciri persamaan yang dimiliki oleh masyarakat Dusun Kimanis ini dengan masyarakat Dusun di daerah lain mampu menggambarkan sebahagian aspek adat resam mereka. Melalui tulisan Pangeran Osman bin O.K.K Pangeran Haji Omar yang berjudul Dusun Custom in Putatan District iaitu berkenaan masyarakat Dusun di Putatan, terdapat sedikit persamaan adat antara masyarakat Dusun di Papar yang terdiri daripada Dusun Tagaas dengan masyarakat Dusun Putatan. Melalui penulisan ini dapat disorot huraian berkenaan adat masyarakat Dusun khususnya di daerah berkenaan. 
Selain itu, menerusi penulisan G.C Wolley tentang Adat-Adat Dusun Di Tambunan dan Ranau pula dapat menjelaskan adat resam masyarakat Dusun khususnya dari aspek kekeluargaan dan pembahagian harta pusaka. Beliau juga ada menyatakan bahawa kaum Dusun sebenarnya berasal daripada satu keturunan yang sama maka tidaklah menghairankan sekiranya masyarakat Dusun di Sabah ini memiliki ciri-ciri persamaan dalam amalan adat resam mereka. Penulisan G.C Wolley juga dapat menjelaskan amalan adat resam masyarakat Dusun di Sabah bukan sahaja daripada aspek sosial tetapi juga yang merangkumi aspek ekonomi.

Dari sudut pentadbiran pula, Sabah ditadbir oleh ketua-ketua yang terdiri daripada golongan penduduk tempatan sendiri. Selain itu, Sabah pernah dinaungi dan ditadbir oleh beberapa buah kerajaan termasuklah Kesultanan Brunei, Kesultanan Sulu, British North Borneo Chartered Company dan Kerajaan British. Perkara ini ada dinyatakan dalam beberapa buah penulisan lepas seperti Sabah The First 100 Years oleh Cecilia Leong, D.S Ranjit Singh dalam The Making of Sabah 1865-1941 serta Peter Phelan dengan judul bukunya Traditional Stone and Wood Monuments of Sabah. Pensejarahan berkenaan pemerintahan Kesultanan Brunei di Sabah khususnya di Kimanis ada dijelaskan dalam penulisan Haji Awang Asbol bin Haji Mail yang berjudul Kesultanan Melayu Brunei Abad ke 19 Politik Struktur Pentadbiran dan penulisan lain beliau iaitu Sejarah dan Pensejarahan Brunei Dinamika Pembentukan dan Transformasi.

Kedua-dua penulisan Haji Awang Asbol tersebut ada menjelaskan secara terperinci berkenaan zaman kegemilangan dan kejatuhan kerajaan Brunei serta kekuasaan kerajaan ini sehingga menakluk banyak kawasan di Sabah. Beliau turut menyenaraikan wilayah-wilayah empayar Kesultanan Brunei pada abad ke-19. Justeru, dapat diketahui bahawa pada ketika itu, Kimanis telah dinaungi oleh seorang wazir dari Kerajaan Brunei iaitu Pangiran Temenggung Hashim sehingga menjelang tahun 1877. Walau bagaimanapun, masih agak kurang penulisan secara terperinci yang memfokuskan sejarah Kimanis dan adat resam masyarakat Dusun di daerah ini. Kebanyakan adat resam masyarakat Dusun hanya dapat dirujuk melalui penulisanpenulisan lepas seperti Pangeran Osman bin O.K.K Pangeran Haji Omar, Peter Phelan, G.C Wolley serta beberapa penulis lain kerana kebanyakan adat resam masyarakat Dusun di Sabah memiliki ciri persamaan yang hampir serupa. Oleh sebab itu penjelasan berhubung penghapusan adat resam masyarakat Dusun di Kimanis dalam artikel ini kebanyakannya diperolehi melalui kaedah temu bual bersama bekas Ketua Adat masyarakat Dusun di Kimanis dan beberapa orang informan lain yang dipilih dalam kajian ini.

\section{Metod Kajian}

Data-data dalam penulisan ini diperoleh melalui kajian kepustakaan iaitu terdiri daripada sumber primer dan sekunder di samping kajian lapangan yang telah dilaksanakan di Kimanis. Olahan data dibuat berdasarkan maklumat daripada kajian-kajian daripada terdahulu di samping hasil temu bual yang dilakukan terhadap Ketua Adat masyarakat Dusun di Kimanis, Ketua Daerah Papar dan beberapa orang informan dalam kalangan masyarakat Dusun di Kimanis yang mempunyai pengetahuan berkenaan adat resam masyarakat mereka. Melalui kaedah ini, dapat mengenalpasti jenis-jenis adat yang sudah dihapuskan atau adat yang sudah tidak diamalkan lagi sejak zaman pentadbiran BNBCC. 


\section{Hasil Dapatan Kajian}

\section{Konsep Adat}

Mohd Salleh Haji Ahmad 1999, berpandangan bahawa adat merupakan satu amalan manusia sama ada perbuatan atau perkataan yang diamalkan secara sukarela dan diwarisi sejak dahulu kala tanpa putus (Pg Ismail, et. All, 2018:15). Menurut undang-undang Islam, perkataan adat berasal daripada istilah adah yang membawa maksud berulang kali atau urf yang ditakrifkan sebagai kebiasaan masyarakat dalam menjalani kehidupan seharian. Dalam hal ini, adat dapat dikaitkan dengan sesuatu perilaku, amalan dan kepercayaan yang menjadi kebiasaan dalam sesebuah masyarakat.

Adat secara umumnya membawa makna kebiasaan yang dilakukan oleh sesebuah masyarakat dan kebiasaan ini akhirnya menjadi satu peraturan hidup yang perlu diikuti dan dikuatkuasakan secara tidak formal. Di samping amalan adat juga diwujudkan hukuman yang sesuai mengikut kesalahan masing-masing jika adat berkenaan tidak dilaksanakan. Namun demikian, pandangan berkenaan adat antara orang Islam dengan masyarakat yang mengamalkan amalan animisme adalah berbeza kerana agama Islam sendiri menggalakkan penganutnya untuk mematuhi syarak yang telah ditetapkan dalam Islam seperti yang sudah tertulis di dalam al-Quran dan as-Sunnah. Bagi orang yang mempercayai amalan animisme pula menganggap bahawa setiap apa yang berlaku datangnya daripada makhluk halus akibat daripada perbuatan manusia sendiri tidak kira sama ada baik ataupun buruk. Hal ini bertitik tolak daripada amalan kepercayaan animisme yang mempercayai kuasa ghaib seperti hantu, polong, puaka, orang bunian dan penunggu di sesuatu kawasan.

\section{Era Pemerintahan Kesultanan Brunei di Sabah}

Ketika Kesultanan Brunei memerintah Sabah iaitu sebelum tahun 1881, Sultan Brunei tidak pernah menghalang penduduk tempatan membuat sebarang peraturan dalam kalangan suku kaum mereka sendiri khususnya melibatkan adat resam dan undang-undang tradisional mereka. Malahan, Sultan Brunei turut memberikan hak pentadbiran kepada penduduk tempatan menerusi institusi pentadbiran peribumi yang melibatkan ketua-ketua tempatan untuk mentadbir mengikut suku kaum masing-masing. Walaupun pada ketika itu Sultan Brunei mempunyai kuasa bukan sahaja memerintah malah mengutip cukai terhadap penduduk di wilayah jajahan Brunei.

\section{Era Pentadbiran British North Chartered Company di Sabah}

Apabila BNBCC mula mentadbir Sabah selepas tahun 1881, BNBCC telah merancang beberapa strategi untuk memastikan kedudukan mereka tidak tergugat malahan mereka menginginkan kuasa mereka berkekalan dengan cara mempengaruhi minda masyarakat tempatan untuk patuh kepada arahan-arahan pentadbiran mereka. Pelbagai usaha yang dilakukan oleh pentadbir BNBCC bagi memastikan kuasa mereka tidak diganggu gugat oleh kuasa asing begitu juga dengan penduduk tempatan sendiri. Namun begitu, hal ini akhirnya menemui hasil yang tidak diingini oleh BNBCC apabila ada sebahagian penduduk yang bangkit menentang pentadbiran BNBCC terutamanya pada zaman-zaman awal pentadbiran BNBCC di Sabah. 
Namun demikian, keadaan di Kimanis pula berbeza berbanding di beberapa kawasan lain seperti Keningau dan Tenom kerana tidak ada siri penentangan dilakukan terhadap BNBCC. Pada ketika itu masyarakat hanya mengikuti perintah walaupun sedikit demi sedikit amalan dan adat tradisi mereka semakin kurang diamalkan akibat daripada dasar yang dibawa oleh BNBCC. Pada ketika ini, BNBCC menggunakan cara terbaik bagi mengelakkan penentangan dalam kalangan masyarakat tempatan iaitu menghormati adat masyarakat peribumi walaupun dalam bentuk tidak bertulis (NBH Official Gazette, Kudat,1883). Merujuk kepada artikel 9 British North Borneo Chartered Company 1881 dalam penulisan Peter Phelan iaitu;

In the administration of justice by the company to the people of Borneo, or inhabitants thereof, careful regard shall always be had to the customs and laws of the class or tribe or nation to which the parties respectively belong, especially with the respect to the holding, possession, transfer and disposition of lands and goods, and testate on intestate succession thereto and marriage, divorce and legitimacy and other rights of property and personal rights (Peter Phelan, 2003:7).

\section{Jenis-Jenis Adat Resam yang Dihapuskan}

\section{Adat Perkahwinan (Bermadu)}

Semasa zaman BNBCC, hanya adat perhambaan sahaja yang telah dihapuskan oleh BNBCC secara besar-besaran. Namun, dalam penulisan ini, penulis memfokuskan dua jenis adat resam masyarakat Dusun di Kimanis yang terhapus iaitu adat perkahwinan (bermadu) dan adat punggo. Namun, penghapusan amalan adat resam tersebut bukan atas sebab perintah daripada BNBCC secara langsung, tetapi adalah disebabkan oleh dasar BNBCC dan kemunculan pengaruh agama. Adat perkahwinan merupakan satu bentuk amalan yang sering dilakukan bagi menemukan pihak lelaki dan perempuan dalam sesebuah masyarakat. Namun, adat perkahwinan turut memiliki pantang larangnya yang tersendiri dan perlu dipatuhi agar tidak menyalahi adat dan tatasusila masyarakat. Masyarakat Dusun sendiri menganggap bahawa adat dalam perkahwinan amat penting bukan sahaja untuk menjaga ketatasusilaan, malahan turut menjadi identiti masyarakat agar lebih mudah untuk dikenali. Namun demikian, peredaran masa dan zaman menjadikan sebahagian daripada adat perkahwinan semakin lama mengalami perubahan iaitu kurang diambil berat tentang betapa pentingnya amalan ini diteruskan.

Salah satu adat yang tidak diamalkankan lagi oleh majoriti dalam kalangan masyarakat Dusun di Kimanis ialah adat bermadu iaitu khusus bagi seorang suami yang ingin berkahwin sekali lagi dengan wanita lain dalam erti kata lain ialah berpoligami menurut agama Islam. Mereka menganggap adat bermadu perlu dilakukan dengan cara membayar sogit atau denda kepada isteri pertama untuk tujuan membela pihak yang terkilan kerana masyarakat Dusun mendakwa bahawa berkahwin lebih daripada seorang adalah salah menurut adat kerana akan melukai hati isteri pertama. Apabila seorang suami membuat keputusan hendak berkahwin lagi, maka suami tersebut harus membayar sogit seekor kerbau dan duit belanja setiap bulan kepada isterinya. Namun, sekiranya pasangan ini memiliki anak hasil perkahwinan mereka, maka suami perlu membayar sogit seekor kerbau untuk setiap anak bergantung kepada bilangan anak mereka.

Sebagai contohnya, jika bilangan anak mereka seramai empat orang, maka perlu membayar sogit sebanyak empat ekor kerbau kepada anak-anaknya. Begitu juga dengan bakal 
isterinya yang kedua perlu membayar sogit seekor kerbau kepada isteri pertama. Walau bagaimanapun, adat bermadu tidak lagi digunapakai dalam kalangan masyarakat Dusun atas sebab kemunculan agama Kristian dan Islam yang semakin berkembang semenjak kedatangan Kesultanan Brunei dan Sulu yang membawa pengaruh Islam serta berlakunya perkembangan pengaruh Kristianisasi oleh pihak BNBCC di Sabah.

\section{Adat Punggo}

Adat punggo merupakan sebahagian daripada adat pusaka iaitu adat yang digunakan ketika pembahagian harta pusaka yang tinggalkan oleh ibu bapa mereka. Adat ini diguna pakai sejak tahun 1517 di Sabah kemudiannya mulai kurang diamalkan hingga pada akhir tahun 1950-an. Adat ini sudah tidak digunakan hingga ke hari ini. Dalam adat punggo, prinsip kejujuran dan keadilan dapat dilihat secara jelas sama ada anak sulung bersikap sedemikian ataupun sebaliknya. Dalam adat ini, anak sulung akan diberi kuasa sepenuhnya oleh ibu bapa untuk membahagikan harta secara sama rata kepada adik-beradik yang lain setelah ibu bapa mereka meninggal dunia. Sekiranya anak sulung memiliki sifat yang adil dan jujur, maka pembahagian harta yang diwarisi akan dibahagikan secara sama rata. Namun sebaliknya berlaku jika anak sulung mempunyai sifat tamak dengan mengambil semua harta tanpa membahagikannya secara sama rata kepada adik beradik atau pewaris harta yang lain. Dalam pelaksanaan adat punggo, Orang Tua akan campur tangan untuk menasihati anak sulung dan selebihnya bergantung kepada budi bicaranya kerana hak kuasa pembahagian telah diserahkan sepenuhnya kepada anak sulung. Pemberian hak kuasa pembahagian harta ini dilakukan oleh ibu bapa mereka sendiri dan bukannya daripada Orang Tua, Ketua Kampung mahupun mahkamah. Oleh itu, menurut masyarakat Dusun di Kimanis, adat punggo ini amat bergantung kepada budi bicara anak sulung dan tidak ada kuasa yang boleh mengatasinya.

Dalam hal ini, wujudnya kebimbangan dalam kalangan ibu bapa yang hendak mewariskan harta pusaka sekiranya mereka sudah tiada. Pada zaman dahulu adat punggo perlu dilakukan khususnya dalam konteks pembahagian harta oleh sebab belum wujud mahkamah sebagai kuasa menentukan sesuatu hak untuk menjalankan proses pengadilan dan perbicaraan malahan hanya bergantung kepada peranan Orang Tua dan Ketua Kampung. Oleh yang demikian, apabila BNBCC mentadbir Sabah, beberapa mahkamah mula ditubuhkan bagi memudahkan masyarakat untuk menuntut atau menyelesaikan sesuatu kes mengikut bidang kuasa mahkamah.

Adat punggo ini semakin lama semakin kurang diamalkan kerana kebanyakan ibu bapa akan menyerahkan warisan harta pusaka lebih awal mengikut penama yang telah ditetapkan. Pada ketika ini, Orang Tua akan menjadi saksi dan penyerahan akan diberikan kepada waris sesuai mengikut kehendak ibu bapa mereka. Hal ini bertujuan untuk mengelakkan daripada berlakunya ketidakadilan dalam pembahagian harta kerana bimbang akan menimbulkan perasaan dendam dan iri hati dalam sesebuah keluarga. Di samping itu, kewujudan Mahkamah Anak Negeri sejak tahun 1913 telah menyebabkan kes-kes yang berkaitan tuntutan hak dan harta pusaka semakin mudah untuk diselesaikan. Malahan sekiranya berlaku sebarang penyelewengan dalam perihal ini, maka mahkamah akan mengambil tindakan yang sewajarnya. Hal in menyebabkan adat punggo semakin lama semakin mengalami kepupusan apatah lagi dengan pengaruh agama Islam serta Kristian yang masing-masing agama mempunyai cara yang tersendiri untuk menyelesaikan masalah sedemikian mengikut peraturan ajaran agama berkenaan. 
Selain itu, terdapat beberapa jenis adat resam yang sudah tidak diamalkan oleh masyarakat Dusun dan untuk bahagian ini penulis memfokus kepada adat kematian khususnya berkaitan dengan pantang larang sepanjang tempoh berkabung. Sesiapa sahaja yang hidup atau bernyawa pasti akan menemui ajalnya sama ada cepat mahupun lambat. Merujuk konteks adat resam masyarakat Dusun, adat berkabung sangat terkenal dan wajib untuk dipatuhi apabila berlakunya sesuatu kematian. Berkabung membawa maksud tanda kesedihan atas kepergian seseorang sama ada ahli keluarga, kenalan ataupun orang terhormat. Kebiasaannya proses berkabung berlangsung selama tujuh hari dan pemakaian kain putih atau hitam digunakan bergantung kepada pegangan masing-masing. Bagi masyarakat Dusun, adalah menjadi satu kesalahan besar sekiranya seseorang itu melanggar pantang larang adat berkabung kerana akan dianggap tidak menghormati jenazah simati.

Dalam erti kata lain, adat berkabung ini diamalkan adalah untuk mengelakkan seseorang daripada tersebarnya fitnah. Oleh itu banyak pantang larang yang perlu dipatuhi misalnya seorang balu tidak boleh keluar rumah atau pergi ke rumah orang lain selama tujuh hingga ke 30 hari sepanjang hari berkabung. Oleh sebab bimbang munculnya malapetaka yang akan dibawa oleh balu (isteri yang kematian suami) sekiranya balu berkenaan pergi ke rumah orang lain walaupun di rumah adik-beradik atau sanak saudaranya sendiri melainkan mendapat keizinan daripada tuan rumah tersebut. Lebih daripada itu, seorang balu juga perlu mematuhi pantang larang dalam memilih makanan ataupun berpantang. Ada beberapa jenis makanan yang tidak boleh dimakan oleh seorang balu sepanjang tempoh hari berkabung antaranya ikan keli, cili, rebung dan keladi. Setiap jenis makanan tersebut mewakili tanda-tanda yang kurang baik dan perlu dijauhi buat sementara waktu sehingga habis hari berkabung.

Jika seorang balu yang memakan keladi dalam tempoh hari berkabung, dipercayai bahawa akan ada lelaki yang cuba mendekatinya sedangkan dia baru sahaja kehilangan suami. Berikutan daripada tanggapan tersebut, mereka mempercayai bahawa keladi itu akan menyebabkan anggota badan menjadi gatal, maka mereka mengaitkannya dan mengelakkannya daripada dimakan oleh balu sepanjang hari perkabungan kerana khuatir akan diganggu oleh lelaki atau perempuan lain. Di samping itu, orang kampung turut menganggap balu tersebut tidak menghormati suaminya yang baru sahaja meninggal dunia. Maka, balu berkenaan akan dikenakan sogit seekor kerbau dan diserahkan kepada ibu atau bapa mertuanya sebagai tanda permohonan maaf dan kekesalan. Dalam hal ini jelas sebenarnya adat berkabung adalah bertujuan untuk mengelakkan daripada timbulnya sebarang fitnah dan sebagai tanda masih bersedih atas kehilangan pasangan. Namun begitu, adat berkabung ini sudah kurang diamalkan sejak zaman pentadbiran BNBCC hingga kini kerana generasi baharu khususnya pada masa kini sudah ramai yang mempunyai pegangan agama sendiri. Hanya segelintir masyarakat Dusun yang mengamalkannya dan pengamalnya juga terhad kepada orang yang benar-benar berpegang kepada adat tradisional sahaja.

\section{Faktor-Faktor Penghapusan Amalan Adat Resam Masyarakat Dusun di Kimanis}

Sebelum wujudnya pengaruh agama Islam dan Kristian di Sabah, masyarakat mengamalkan kepercayaan animisme iaitu mempercayai wujudnya semangat dan roh terhadap alam malah masyarakat Dusun tradisional amat berpegang teguh dengan kepercayaan tersebut. Penduduk peribumi Sabah secara umumnya menerima pengaruh agama samawi melalui cara yang berbeza-beza. Misalnya, hanya sebahagian kawasan sahaja yang mengalami perkembangan pengaruh Islam khususnya di pantai barat yang dibawa oleh Kesultanan Brunei dan di bahagian 
pantai timur mengalami perkembangan Islam melalui Kesultanan Sulu (Suraya Sintang, 2003:67).

Hal ini tidak jauh bezanya dengan perkembangan agama Kristian yang dibawa oleh pihak BNBCC secara langsung dan peranan para mubaligh Kristian yang datang ke Borneo untuk menyampaikan dan menyebarkan pengaruh Kristian (Suraya Sintang, 2003, 59-80). Pengaruh agama Kristian jelas lebih besar berbanding Islam khususnya di kawasan pedalaman Sabah seperti Ranau, Keningau, Tambunan, Kiulu dan termasuklah Ulu Kimanis berikutan daripada proses perkembangan Islam yang agak perlahan di beberapa kawasan ini akibat daripada kesukaran mobiliti dan akses.

Justeru, ramai masyarakat Dusun di Kimanis yang menerima ajaran agama Kristian berbanding Islam dan hal ini akhirnya membawa masyarakat untuk lebih mengenali agama tersebut dengan lebih mendalam. Maka, bilangan masyarakat yang mengamalkan kepercayaan animisme semakin berkurangan sehingga menyebabkan sebahagian adat resam tidak diamalkan kerana berbeza dari sudut kefahaman berkaitan ketuhanan dan alam. Manakala, bagi segelintir masyarakat Dusun yang memeluk agama Islam pula akan mengikut syariat Islam dan sudah pasti jauh berbeza dengan amalan animisme kerana Islam hanya berpegang kepada dua perkara iaitu al-Quran dan as-Sunnah sebagai panduan hidup.

Selain itu, dasar yang dibawa oleh BNBCC secara tidak langsung menyebabkan penghapusan terhadap sebahagian adat resam masyarakat Dusun di Kimanis iaitu melalui pengenalan undang-undang Inggeris di Sabah yang membawa kepada wujudnya campur tangan BNBCC dalam menguruskan masyarakat tempatan. Undang-undang ini dikenali sebagai Common Law iaitu sejenis undang-undang Inggeris yang diguna pakai daripada undang-undang adat lama England kemudiannya diperkembangkan menjadi undang-undang kebangsaan dengan cara dimajukan dan diubahsuai oleh para hakim melalui keputusan mereka yang melibatkan beberapa isu dan akhirnya dibezakan dengan adat tempatan (Ahmad Ibrahim, 1993:1).

Common Law Inggeris diperkenalkan melalui Enakman Undang-Undang Sivil 1937 kepada Negeri-Negeri Melayu Bersekutu kemudian disebarkan secara meluas kepada NegeriNegeri Melayu Tidak Bersekutu dan akhirnya tersebar ke Sabah dan Sarawak. Di Sabah, pemakaian Common Law England dan kaedah-kaedah ekuiti bersama dengan statut-statut pemakaian am berkuatkuasa sama seperti di England pada 1 Disember 1951 sesuai mengikut keadaan dan tidak ada peruntukan undang-undang bertulis pada ketika itu (Ahmad Ibrahim, 2003:2). Salah satu sebab BNBCC memperkenalkan undang-undang baharu kepada masyarakat Sabah adalah kerana pada ketika itu undang-undang di Sabah berbentuk tidak formal. Bertitik tolak daripada hal ini, jelas bahawa undang-undang adat di Sabah dianggap masih berbentuk tidak formal dan belum direkodkan seperti yang dinyatakan oleh Peter Phelan (2003). Malah apabila Sabah dan Sarawak bergabung dengan Persekutuan Tanah Melayu, undang-undang ini digantikan dengan Akta Undang-Undang Sivil 1956 (Phelan, 2003:2).

Pengenalan undang-undang Inggeris ini membawa kepada perubahan dalam bidang kuasa khususnya berkaitan dengan pengendalian sesuatu kes. Jika pada zaman lampau, semua bentuk kesalahan termasuk bunuh, rogol, curi atau apa-apa sahaja yang melibatkan kesalahan jenayah akan diurus dan diselesaikan di bawah bidang kuasa institusi peribumi iaitu melalui hukum adat. Namun, pengenalan undang-undang Barat akhirnya menyebabkan institusi peribumi seperti Mahkamah Anak Negeri hanya mengendalikan kes-kes kecil iaitu berkaitan dengan kesalahan ringan termasuk adat dan tanah. Maka, tidak wujud lagi undang-undang adat 
yang melibatkan proses hukuman mati, sula, rejam dan buang daerah oleh masyarakat Dusun sendiri seperti yang diamalkan pada zaman sebelum pemerintahan BNBCC di Sabah.

Selain itu, faktor seterusnya yang membawa kepada kemerosotan amalan adat resam masyarakat Dusun di Kimanis adalah disebabkan oleh wujudnya penubuhan mahkamah dibawah pemerintahan BNBCC. Sebelum tahun 1920-an mahkamah telah ditubuhkan secara tidak rasmi dan pada ketika ini masyarakat Dusun masih menjadikan rumah Orang Tua sebagai balai perbicaraan sesuatu kes. Hal ini kerana di Sabah masih belum ada bangunan khas yang menempatkan Mahkamah Anak Negeri. Pada tahun 1913, secara rasminya Mahkamah Anak Negeri ditubuhkan dengan termaktubnya Ordinan Mahkamah Anak Negeri dan melantik seorang Ketua Anak Negeri daripada penduduk tempatan sendiri. Penubuhan mahkamah ini membawa kepada konsep formal iaitu mengikut prosedur semasa mengendalikan sesuatu kes.

Berbeza dengan sebelum penubuhan mahkamah, adat lebih bersifat tidak formal. Setiap masalah akan dikendalikan oleh Orang Tua, Ketua Kampung dan Ketua Adat malahan tidak ada sebarang naskah yang bertulis kerana masyarakat hanya berpandukan kepada pengetahuan, pengalaman, budi bicara dan sumber lisan daripada nenek moyang mereka. Penubuhan mahkamah ini akhirnya menyebabkan banyak kes dibicarakan mengikut bidang kuasa Mahkamah Anak Negeri. Contohnya, berkaitan dengan pembahagian harta pusaka, kesalahan moral kecuali melibatkan kesalahan sivil. Di samping itu, penubuhan mahkamah menyebabkan kuasa Orang Tua semakin berkurang kerana BNBCC memperkenalkan beberapa jawatan baharu termasuklah Ketua Anak Negeri serta Wakil Ketua Anak Negeri yang terlibat dalam pengendalian kes-kes penduduk peribumi. Hal ini seterusnya memberi kesan yang mendalam terhadap zaman sekarang kerana kebanyakan ahli yang bertugas dibawah organisasi Mahkamah Anak Negeri khususnya tidak mempunyai pengetahuan dengan lebih mendalam tentang sejarah dan adat resam penduduk tempatan.

\section{Kesimpulan}

Kesimpulannya, bagi masyarakat Dusun Kimanis adalah sukar untuk meninggalkan sesuatu adat yang sudah lama diamalkan sehingga menjadi pegangan dan panduan hidup malahan dianggap sebagai suatu kewajiban untuk dipatuhi. Walau bagaimanapun, tidak dapat dinafikan bahawa peredaran masa dan zaman mampu mengubah pelbagai perkara termasuk pemikiran masyarakat yang dahulunya begitu berpegang teguh dengan amalan adat tradisional. Namun, perubahan tersebut tidaklah bermakna seseorang itu mengkhianati warisan nenek moyang mereka kerana amalan adat resam tradisional masih boleh diteruskan dalam kehidupan harian mereka jika tidak bertentangan dengan amalan agama yang dianuti.

\section{Penghargaan}

Ucapan terima kasih dan penghargaan kepada pihak UMS yang memberi bantuan Skim Bantuan Pascasiswazah dalam kajian ini. Setinggi-tinggi penghargaan juga ditujukan khusus untuk Ketua Adat masyarakat Dusun Kimanis, Encik Palin Along, Ketua Daerah Papar, Encik Ag. Mumin Bin Ampuan Marali, Puan Piche Kumpoh dan Haji Ariffin iaitu penduduk asal Dusun Kiudang kerana telah memberi kerjasama sepanjang kajian ini dijalankan.

\section{Rujukan}




\section{Sumber Primer}

British North Borneo Herald 1883

British North Borneo Herald 1884

British North Borneo Herald 1886

British North Borneo Herald 1887

British North Borneo Herald 1888

British North Borneo Herald 1889

British North Borneo Herald 1890

North Borneo Herald Official Gazette, Kudat, 1st September 1883

\section{Sumber Sekunder}

Jurnal

Suraya Sintang. (2003) Penganutan Agama Islam dan Kristian Di Kalangan Masyarakat KadazanDusun Di Sabah. Jurnal Usuluddin, Bil 18. Hlm 59-80.

Pg Ismail, et. All. (2018). Amalan Sogit Ke Atas Anak Negeri Sabah Beragama Islam Di Mahkamah Anak Negeri: Kajian Dari Perspektif Hukum, Jurnal Islam dan Masyarakat Kontemporari. Bil. 19.

Buku

Awg Asbol bin Haji Mail (2011). Kesultanan Melayu Brunei Abad ke 19 Politik dan Struktur Pentadbiran. Dewan Bahasa dan Pustaka, Brunei.

Awg Asbol bin Haji Mail (2012). Sejarah dan Pensejarahan Brunei Dinamika Pembentukan dan Transformasi. Pusat Sejarah Brunei, Bandar Seri Begawan.

Arena Wati. (1978). Dusun Satu Tinjauan dalam Konteks Kepercayaan, Kultus dan Hukum Adat di Sabah. Penerbitan Yayasan Sabah, Kota Kinabalu.

Leong, C. (1982). Sabah The First 100 Years. Percetakan Nan Yang Muda Sdn.Bhd, Kuala Lumpur.

Eko Prayitno Joko (Penyunting). (2015). Kimanis 600 Tahun, Kota Kinabalu. Unit Penyelidikan Arkeologi Borneo, UMS Kota Kinabalu

Haji Abdul Karim bin Haji Abdul Rahman. (2016). Sejarah Pengasasan dan Asal Usul Kerajaan Brunei Berdasarkan Sumber Lisan. Universiti Malaya, Kuala Lumpur

Hamiddun bin Udin. (1992). Masyarakat Kadazandusun di Ranau: Kajian Identiti dan Interaksi antara Agama. Jabatan Antropologi dan SosiologiUniversiti Malaya, Kuala Lumpur 
Kitingan. J.P. (2012). Kadazandusun. Institut Terjemahan dan Buku Malaysia, Kuala Lumpur.

Lind. R.A. (2003). My Sabah Reminiscences of A Former State Secretary. Natural History Publication (Borneo), Kota Kinabalu.

Madisah. J. (1986). Tatacara Adat Istiadat dan kebudayaan Kadazan. SIKUK Publication, Kota Kinabalu.

Othman Ishak. (1979). Hubungan antara Undang-undang Islam dengan Undang-Undang Adat. Dewan Bahasa dan Pustaka, Kuala Lumpur.

Pangeran Osman bin O.K.K Pangeran Omar. (2006). Dusun Custom in Putatan District. Natural History Publications, Kota Kinabalu.

Phelan. P. (1997). Traditional Stone and Wood Monuments of Sabah. Pusat Kajian Borneo, Kota Kinabalu.

Phelan. P. (2003). The Traditional Legal System of Sabah. Pusat Kajian Borneo, Kota Kinabalu

Ranjit Singh. (2000). The Making of Sabah 1865-1941. University Malaya Press, Kuala Lumpur.

Suwaid bin Tapah. (1988). Sejarah Perundangan Islam di Sabah. Universiti Malaya, Kuala Lumpur.

Suraya Sintang. (2013). Kehidupan Beragama Masyarakat Kadazandusn. Penerbit Universiti Malaysia Sabah, Kota Kinabalu.

Woolley. G.C. January (1953). Kwijau Adat. The Government Printing Department, Jesselton Sabah.

Woolley. G.C. (1953). Hal Ehwal Anak Negeri Bil.2 Adat Tuaran: Sebahagian dari Adat Orang Orang Dusun di Daerah Tuaran, Pantai Barat, Borneo Utara. Pejabat Chap Kerajaan, Jesselton Sabah.

Tesis

Salbiya Binti Jamaluddin, (2016), Penubuhan Mahkamah Anak Negeri Sabah: Bidang Kuasa dan Sumbangannya kepada Anak Negeri 1884-2009, (Tesis Sarjana) Universiti Kebangsaan Malaysia, Bangi. 